\title{
Women's Language in the English Interpretations of the Qur'anic Discourse: Plenty of Verbal Clues that Urge Woman to Keep Face, Be Polite and Tell the Truth
}

\author{
Hala Toubal, Lara Qassas \& Sami Al-Heeh* \\ Department of Applied English, College of Arts, Palestine Ahliya University, Palestine \\ E-mail: samheeh@paluniv.edu.ps
}

\begin{abstract}
This small-scale study explores the rhetorical features of women's language in the Qur'anic discourse. It aims to check the norms of speech the Qur'anic discourse maintains for women as interlocutors. The study utilizes both corpus linguistics, i.e. large body of texts, and discourse analysis as methods of research. For data collection, the study benefits from concordance, i.e. key words in context (KWIK). For data analysis, the study, however, applies critical discourse analysis (CDA). Therefore, it builds on Fairclough's 2013 and Van Dijk's 1998 models of analysis. It has been found that the Qur'anic discourse urges women to keep face, to maintain norms of polite speech and to tell the truth. Finally, the study implicates for pedagogy and research.
\end{abstract}

Keywords: Women's language, Qur'anic discourse, verbal clues, face, norms of politeness, corpus linguistics, critical discourse analysis (CDA).

\section{Introduction}

\subsection{Background of the Study}

In the discipline of sociolinguistics, woman language is a hot topic. Lakoff (1973) suggests that women language is characterized by lexical hedges or fillers, e.g. 'you know, sort of, well, you see', tag questions, e.g. 'she's very nice, isn’t she?', rising intonation on declaratives, e.g. 'it's good!', empty adjectives, e.g. 'divine, charming, cute, precise color terms, e.g. magenta, aquamarine', intensifiers such as 'just and so', e.g. 'I like him so much', hypercorrect grammar, e.g. consistent use of standard verb forms, super-polite forms, e.g. indirect requests, euphemisms, avoidance of strong swear words, e.g. 'fudge, my goodness' and lastly emphatic stress, e.g. 'it was a BRILLIANT performance!'. Since then, researchers have already investigated many of these features. The findings of solid research have already fixed the fact that the terms 'man' and 'woman' probably show two different worlds and words.

Language politeness is another area. It has been found that language serves many functions including the following-according to Holmes (2013, p. p259): First, language function can be expressive as the utterance attempts to show the speaker's feelings, e.g. 'I'm feeling great'. Secondly, it is a directive utterance attempting to get someone to do something, e.g. 'Clear the table'. Thirdly, it is a referential utterance providing some information, e.g. 'At the third stroke it will be three o'clock precisely". Forth, meta-linquistic utterances comment on language itself, e.g. 'Hegemony' is not a common word'. Fifth the poetic utterances focus on aesthetic features of language, e.g. a poem, an ear-catching motto that rhymes as 'Peter piper picked a peck of pickled peppers. Finally, phatic utterances express solidarity and empathy with others, 'HI, how are you, lovely day isn't it!', for instance.

In the world of teaching English as a foreign language (TEFL), Arab learners for instance, are often exposed to some course books that over-generalize the findings of some studies carried on a context to another. Those textbooks claim that many natives in certain eastern culture do not go beyond expressing politeness by certain terms such as 'Thank you' and 'I'm so sorry'. Socially, language politeness entails much more than saying words to taking acts. For example, Holmes (2010) tends to expose Arab learners doing a degree in English to some cultural assumptions based on international studies which assume that the norms and of politeness an Arab woman, for instance, would use when she speaks is like those of Chinese women. It sounds that so many cultural components are taken from the teaching of Islamic culture i.e. a way of life. Culture is a subject matter of specificity. And cultural 
values may vary from one group of people to another within the same context.

In second language acquisition (SLA), Arab learners are often introduced to some published textbooks that tend to over-generalize norms of speech to both men and women according to some geographical and cultural norms. By quantifying as well as quantifying the rhetorical features of certain texts where the terms 'Yes!' and 'No!' used, Al-Hidmi and Abu-Tair (2017) found that Enqlish for Palestine used for $10^{\text {th }}$ graders significantly and subconsciously reinforces disagreement among Palestinian Arab teenagers in on hand. On the other, Face2face, intermediate student book by Redstone \& Cunningham (2013) used at Palestine Ahliva University teaches the student five ways of aqreeinq to include 'Yes, that sounds like a good idea', 'Well. It's (definitely) work a try', 'Yes that's not a bad idea!', 'Yes, that might work', and 'That's a great brilliant idea!' However, the ESL course book teaches only three ways of disaqreeinq including 'I'm not sure about that', 'Sorry, I don't think we should do that' and 'I'm not sure that's a good idea!'. The researchers suggest that the ESL textbook tends not only to maximize ways of agreement but also to minimize ways of disagreement among international learners. It is a polite target the ESL textbooks attempts to meet within the context of learning.

In the field of pragmatics, i.e. language in use, speech is often governed by the general principle of interaction and politeness. Grice's 1975 maxims of conversation include: Truthfulness aiming to qualify speech suggests that communicators should do their best to make their contributions true. Informativeness shooting at quantifying speech mandates that communicators should do their best to be adequately informative. Relevance, however, sustains that communicators should do their best to make their contributions relevant. Finally, style or manner maintains that communicators should do their best to make their contributions appropriately short and clearly expressed. Leech (1983) adds to Grice's cooperative principles the politeness principle which is a necessary supplement to Grice's cooperative principles. He argues that people often break the cooperative principles for politeness reasons. According to Leech, politeness maxims include modesty and agreement.

Technically, the Qur'anic discourse uses certain terms to refer to woman. The singular form 'imra'atun' roughly glossed as 'partner' in modern English, is selected when there is a full disagreement between partners who tend adopt different attitudes and approaches to life. In chapter 11 for instance, the Quranic discourse reads "And Allah sets forth for those who believe the example of the wife of Pharaoh when she said, 'My Lord! build for me a house with Thee in the Garden; and deliver me from Pharaoh and his work and deliver me from the wrongdoing people;" (At-Tahrim 66:11). The term is also used to refer to the wife who turns to be old and incapable to give birth due to age. In chapter 51, the Quranic discourse reports that Sarah, Abraham's wife "came forward crving and smote her face and said, "A barren old woman!" (Al-Dharivat: 51:29). Differently, the Quranic discourse inclines to use the singular form 'zawiun' and 'azwaiun' glossed as 'couples' in modern English when there is a full agreement and sexual ability between partners of one functional family. For example, the Qur'anic discourse exclaims "O Prophet, we have made lawful to thee thy wives whom thou hast paid their dowries." (AL-Ahzab 33:52). Elsewhere, the term 'nisa'un' glossed as 'women' or 'females' is used throughout the Qur'anic discourse. The Qur'anic discourse confirms that "... there shall be no blame on you in throwing out a hint regarding a proposal of marriage to these women." (Al-Baqarah 2:35).

\subsection{Research Problem, Objectives and Questions}

As norm of politeness are prevalent as well as bound to culture, Arab learners in general, and females, are often exposed to some international textbooks that introduce the Palestinian Arab cultural with a broader context that covers the cultures in Asia in terms of geography due to scarcity of the studies carried of a Palestinian, specific culture. To fill the gap as well as the void in the literature and to meet the claim that the Palestinian culture thrives on the Qur'anic discourse, the researchers carry out this small-scale study. Thus, the paper will be the first (up to our best knowledge) to explore the Qur'anic Discourse (QD) to identify the syntactic features of the reported verses that give turn to woman to handle speech as well as the direct verses that address women. Therefore, it aims to describe the rhetorical features of these QDs, interpret the general principles of interaction the QDs sustain for woman to interact and explain the forces lying behind the Qur'anic selection and use. The description process of the syntactic features of the QD is supposed to tell how certain meanings are produced whereas the interpretation analysis is supposed to deal with how meanings are produced. The explanation process attempts to explain the non-linguistics factors that govern the principles the QD 
maintains for an Arab or rather a Muslim woman.

To achieve the general goal as well as the objectives of the study, this paper addresses the following questions:

1. What are the general syntactic and rhetorical features the QD acknowledges about women language?

2. What are the general principles of speech the QD maintains to govern women language at specific events?

3. What are the forces and proclivities lying behind the QD selection and choice of words in woman language?

\subsection{Significance of the Study}

The study counts as it will be the first to quantify as well as qualify the syntactic, semantic and schematic features of a precise Script that governs the life including norms of speech and politeness of Palestinian females for ages. It is expected that the study will critically reveal the speech norms the QD highlights for woman when she addresses others. The study is also supposed to unearth the norms of speech others should maintain when addressing females. As the study suggests a critical approach to data analysis, it is expected that the forces lying behind the norm selection and choice is going to manifest themselves. The study will check the role of context on the Qur'anic selection of the speech norm to pass. For these reason, the researchers hope that the study contributes to knowledge and bridges the void as well as the gap in the literature.

\section{Literature Review}

\subsection{Introduction}

This chapter aims at reviewing the scholarly studies carried on gender, women language and politeness. To meet novelty and relevance, this paper overviews the solid research conducted in the field of linguistics, applied linguistics and sociolinguistics in the last two decades. As the study deals with gender in general and woman language, the research will refer to Lakoff's study, the start points in which the area has started.

\subsection{An Overview of Literature}

Jinyu (2014, p.92) studied gender differences in linguistics and sociolinguistics. The researcher claimed that human beings not only created language, but also became the users. As a result, the study on linguistics should not only be made from the perspective of symbol, but more should be people-oriented. The researcher argued that the most significant difference between human beings was the gender difference, so people of different genders from either psychology or physiology in the use of language would have their own gender characteristics, which lead to the gender differences in language. By analyzing and studying on the connotation of gender differences in language and the social sources of it, the researcher concluded the significance of gender differences in language.

Xia (2013, p.1485) investigated the differences between men and women in using language. Besides the differences in various aspects, the researcher mainly discussed the differences from the aspects of syntax, manner, vocabulary, pronunciation, intonation, vocabulary, syntax, and non-verbal differences in using language between women and men. In the paper, the researcher tried to record the changes of these differences. Based on those changes and differences, the paper also tried to make some explanations to those changes and differences.

$\mathrm{Gu}$ (2013) examined the similarities and differences in the notions of language and gender. The researcher studied the relationship between language and gender with focus on differences between the language of male and female from different angles with different methodologies. It had been found different emphasis on the differences, but there were some problems in the researches. The paper also reviewed the previous researches into gender differences, pointed out the problems existing in methodology and research findings, and finally proposed that other researchers should pay more attention to the similarities between the languages of both genders. And he found that the similarities 
play the same important part as well as differences.

Shepherd (2010, pp. 143-159) checked women armed conflict and language- gender, violence and discourse. He argued that facilitating critical reflection on the words and concepts used to write policy enabled practitioners to avoid unconsciously reproducing the different forms of oppression and exclusion that their policies seek to overcome. In the article, the researcher supplied an analysis of Chapter 5.10 of the United Nations Integrated Disarmament, Demobilization and Reintegration Standards. He argued that policy makers, scholars, students and practitioners could not avoid making and/or changing meaning through their well-meaning interventions, but that this need not lead to political or practical inertia.

Argamon, Koppel and Pennebaker (2007) minded the notion of mining the blogosphere, gender, age and the kinds of self-expression. The researchers argued that the growth of the blogosphere offered an unprecedented chance to study language and how people use it on a large scale. They presented an analysis of over 140 million words of English text drawn from the blogosphere, exploring if and how age and gender affected the topic and writing styles. They found that several stylistic and content-based indicators were significantly affected by both age and gender, and that the main difference between older and younger bloggers, and between male and female bloggers, stemmed from the extent to which their discourse was outer- or inner-directed. In fact, the linguistic factors that increased in use with age were iust those used more by males of any age, and conversely, those that decreased in use with age were those used more by females of any age.

In an essay, Broad bridge and Learning (2003, pp. 1-26) investigated the differences between men's and women's speech. They discussed gender differences in language using a recording of a conversation recorded by the writer. The essay detailed the background of research within this area. Then, it moved on to analyze the recording, considering comparisons that could be made between the research carried out here and previous studies in the field. It also included a discussion of relevant issues which arose from the analysis of that research.

Eliasoph (1987, pp.70-103) studied politeness, power and women's language. The researcher argued that there were, in most of these studies, drastic differences between men's and women's language. He claimed that whatever distinguished women's talk from men was interpreted as a sign of powerlessness. It would clearly be impossible, then, for a woman to talk differently from a man without the researcher's devaluing her speech. The swarms of "facts" which researchers had "found" were buzzing around with no theoretical nest but the one automatically provided by an unintentionally sexist ideology. He also suggested that data collectors assumed that facts were discovered "out there," not generated in the nest of one's theory. Where no consciously articulated theory incubated and housed the facts, i.e. the ideology of patriarchy slid in to do the job. What made women's language powerless -but not what kind of context let women speak in a way comfortable to them, had to be the original theorists should ask.

Finally, Lakoff (1973, pp. 45-79) originated women language. He argued that our use of language embodied referential meanings as well as attitudes. Woman's language had founded the attitude that women were marginal to the serious concerns of life that were pre-empted by men. The marginality and powerlessness of women was reflected in both the ways women were expected to speak, and the ways in which women were spoken of. In appropriate women's speech, strong expression of feeling was avoided, expression of uncertainty was favored, and means of expression regarding subject-matter deemed 'trivial' to the 'real' world were elaborated. Lakoff also added that speech about women implied an object, whose sexual nature required euphemism, and whose social roles were derivative and dependent in relation to men.

According to Lakoff (ibid), the personal identity of women was linguistically submerged; the language worked against treatment of women, as serious persons with individual views. These aspects of English were explored regarding lexicon (color terms, particles, evaluative adjectives), and syntax (tag-questions, and related aspects of intonation in answers to requests, and of requests and orders), as concerns speech by women. Speech about women was analyzed regarding lady: woman, master: mistress, widow: widower, and Mr., Mrs., Miss, with notice of differential use of role terms not explicitly marked for sex (e.g. professional) as well. Some suggestions and conclusions were offered for those working in the women's liberation movement and other kinds of social reform; second language teaching; and theoretical linguistics. Lakoff implicated that relevant generalizations in linguistics required study of social mores as well as of purely linguistic data. 


\section{Materials and Methods}

This chapter aims at introducing the theoretical framework for the study and the research method used for both data collection and analysis.

\subsection{Theoretical Framework}

Theoretically, the paper draws on a mixed linguistic theory of language. It fits into the general fields of applied linguistics, sociolinguistics, i.e. language, gender and politeness, semantics or rather pragmatics and (to some extent) stylistic translation. The study consistently builds on "systemic functional language" (SFL) which is supposed to leak some knowledge about the grammatical functions as well as the syntactic features of the units of language under analysis (N. Schmitt, 2010, pp. 55-73). From a pragmatic view, the analysis also builds on "first order logic" to purify meaning (Kearns, 2000, pp. 2535). Therefore, the "meaning relation" that each pair of words under investigation helps build will be analytically checked. The "meaning values" of the antonyms in context will be also drawn (Kearns, 2000, pp. 35-41).

According to Schmitt (2013, p. 55) a normal day will, very likely, starts with discourse, for example, greeting members of the family and some items of news from the radio, TV, WWW, or printed papers, before rushing to school or work. Then, the day continues with a variety of discourse in the institution you get involved in: discussing plans at a business meeting, writing an essay in the library, ordering lunch at a fast food outlet. The flow of discourse over a few days enables you to get a good sense that life is made up of discourse.

The potential goal in ELT is probably learning to engage in discourse. It is likely to be one of the most important goals in language learning and teaching. This means that the study of discourse is "absolutely central to the concerns of applied linguistics" (Schmitt, 2013, pp. 56-59). This also means that it is very helpful to develop an ear for discourse to learn to attend the different strands of patterning in discourse and to focus on context and learning strategies.

Analysts study texts, whether spoken or written and whether long or short. They are interested in the relationship between "texts and contexts" (Schmitt, 2013, pp. 60-73) in which they arise and operate. They look at real texts in a way which is completely different from grammarians and philosophers of language. Analysts raise and try to set answers for certain questions, such as: How do we know what the writers and speakers mean? What does this piece of language mean in this context? What factors enable us to interpret the text? They are simply the questions the researchers raise in this study.

\subsection{Research Methods}

For data collection, the study benefits from corpus (also known as text analysis). According to Reppen and Simpson (2013) corpus linguistics uses large collections of both spoken and written natural texts (corpora or corpuses) that are stored in computer (Schmitt, 2013, pp. 92-111). CL provides tremendous insights as how language use varies in different situations, such as spoken versus written or formal conversations versus casual conversation. Data from the Quranic discourse (QD) will be collected by a concordance program to provide key words in context (KWIK). To generate a concordance list showing the co-occurrence lexical pattern, a target word or phrase needs to be selected. For this study, KWIKs will include certain words namely [qa:lat] meaning 'she said', [qulnna] meaning 'they - the women- said', [tash-hadu] meaning 'she testifies'... etc. Once the search word/phrase is selected, the program can search the text in the corpus and provide a list of each occurrence of the target word in context. The researchers also exploit the English interpretations of the quotes collected from holy Script of Islam, i.e. the QD, provided by www.alislam.org.

The study also benefits from critical discourse analysis (CDA) as a research method. It builds on Van Dijk's 1998 model of analysis which includes discourse as an indispensable component of an ideology. Van Dijk (1998) has identified a variety of discourse structures that can carry important functions of ideology at the syntactic, semantic and schematic levels. The study also meets Fairclough's 2013, 2010 model of analysis. Fairclough's 2013 three-dimensional analytical framework includes three types of analysis at the levels of producing, consuming and construing, i.e. realizing, meaning (Mirzaei and Eslami, 2013, p106). The first analysis is descriptive; it aims at describing the meaning produced. The 
second is interpretive; it aims at consuming the meaning produced by the writer or speaker. The last analysis is explanatory as it aims at realizing the meaning produced and consumed.

\section{Discussion and Analysis}

\subsection{Introduction}

To be consistent, the researchers have already deigned a grid including four columns to help realize the data collected (see Appendix 1). The first column displays the quotes collected from the QD and their interpretations in English; the second column shows the syntactic features of the quotes under study; the third discloses the semantic analysis; the last attempts to view the forces lying behind the QD selection and use of certain words. When analyzing data, the researchers will systematically and objectively describe the rhetorical features of the QD to help realize how certain meanings related to women are produced, interpret the predicates and their arguments to understand how the norms related to women are consumed and explain the forces and proclivities lying behind the selection of certain norms of speech for woman to follow. The syntactic analysis includes checking the linguistic styles and process used whereas the semantic analysis entails checking the predicates, i.e. what is said about the subject and argument. Finally, the schematic analysis shoots at identifying the linguistic as well as the contextual factors that govern the norms of speech the QD fixes for -say a Muslim woman.

In this section, the analysts use a systematic approach to the quotes collectied from the Quranic discourse. For each quote, a syntactic analysis is carried out first. Then a semantic analytical approach is implemented, and finally a schematic analysis is also presented in sub-sections for full organization.

\subsection{Keeping Face and Fixing Norms of Polite Speech}

At the syntactic level, three language styles are used in quote $1 \mathrm{~A}$ : the verbal, the nominal and the semiverbal. The verbal style is used once to report what Sarah, Abraham's wife said. The nominal style is used three times to say that she is an old woman, that her husband is old and that that thing is so strange. It is important to note here that the nominal style helps package, i.e. load meaning. Finally, the semi-verbal style is used once to express exclamation about giving birth at an old age. It's important to note that the semi-verbal style, having the general features of both other styles (nominal / verbal) is used to show exclamation and direction (see Quote 1A).

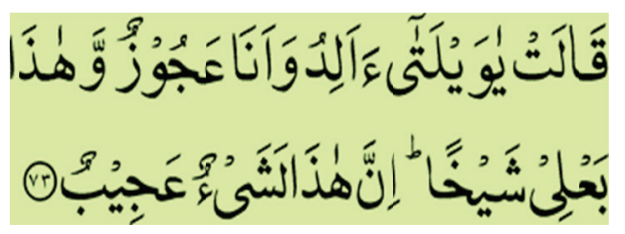

Quote 1A [qa:lat ya:-waylati: 'a-alidu wa-ana: 'aju:zun wwa-hatha: ba'li: shaykhan inna hatha: lashay'un 'aji:bun] Hud 11:72

She said, 'Oh, woe is me! Shall I bear a child when I am an old woman, and this my husband is an old man? This is indeed a strange thing!'

At the semantic level, quote 1A uses six predicates namely SAY, OH, BEAR, AN OLD WOMAN, MY HASBAND and BE STRANGE THING.A predicate is what is said about the subject and other arguments. Predicate one SAY argues to (she) referring to Sarah, Abraham's wife. Therefore, it is a onepredicate verb phrase. Predicate two OH! does not refer to any argument as it navïgates a non-linguistic element. Predicate three BEAR argues to (I) referring to Sarah. Predicate four AM OLD WOMAN argues for (I) referring to Sarah. Predicate five BE MY HUSBAND argues for (this) demonstrating to her husband. Predicate six BE STRANGE THING argues to (this) referring to giving birth at old age. It is important to note here that the demonstrative pronoun [hatha:] meaning (this) is used twice. As the first signals for Abraham as an old, this demonstrative pronoun is endophoric. The later pronoun signals to the whole idea of giving birth at an old age. Thus, it is exophoric. 
At the schematic level, quote, $1 \mathrm{~A}$ explores some predicates and arguments in some women's language expressing giving birth at old age. This hard forced the woman to select and use some words that attempt to hedge for her positive as well as negative face. A positive face is the public image each one of us wants the other to keep for him or her. The negative face is, however, the same public image anyone of us wants to keep and not to go further. The word used and selected by Sarah also attempts to mirror norms of politeness. Being polite is usually carried out by two maxims: Agreement and self-dispraise. The agreement principle sustains maximizing agreement as well as minimizing disagreement with others. By the selection of certain words, such as 'I'm very old' and 'My husband is too old', Sarah attempts to dispraise herself. By doing so, she looks polite.

By the same token, quote 1B syntactically uses two language styles. Semantically, it uses three predicates namely DRIVE, SAY and DIE. Finally, schematically, quote 1B hedges for both keeping face and being polite. In the Quote, the selection of the exclamation 'OH!' tries to keep face, i.e. the public image that Mary tries to keep for herself as well as for her miraculous kid, Jesus the Christ. The use of certain words, such 'a forgotten thing' attempts to meet the norms of polite speech by dispraising herself to the bare minimum.

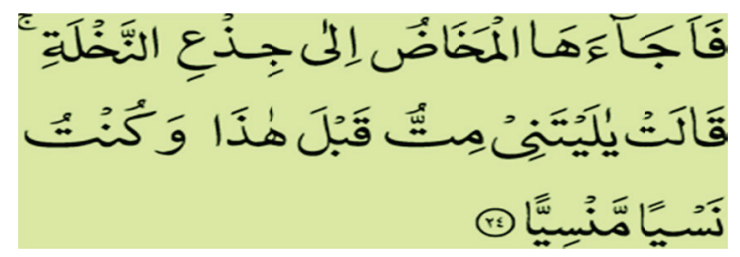

Quote 1A [fa-'aja:'aha: al-makha:du ila: jith'i an-nakhlati qa:latya:-laytani: mittu qabla hatha: wakuntu nasyyan mmansiyyan] Maryam 19:23

And the pains of childbirth drove her unto the trunk of a palm-tree. She said, 'O! would that I had died before this and had become a thing quite forgotten!'

\subsection{Keeping Face and Telling the Truth}

To proceed at the syntactic level, three language styles are used in quote $2 \mathrm{~A}$ : the verbal, the nominal and the semi-verbal. The verbal style is used seven times, to report what the king (of ancient Egypt) said, to report what was the matter, to report the women who seduced Joseph, to report what the women said, to report what the king said, to report that the truth came out and to report that wife of Aziz seduced Joseph. The nominal style is used twice to say that the women did not know and to tell that she (the wife) is telling the truth. Finally, the semi-verbal style is used once to deny the accusation of harassment to Joseph. (see Quote 2A)

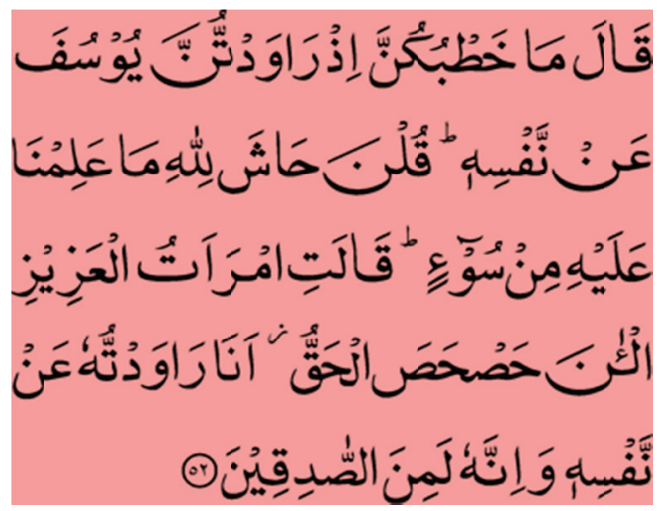

Quote 2A [qa:la ma: khatbukunna ith rawadtunna yu:sufa 'an nnafsihi qulnna hasha: li-Allah ma: a'limnaa 'liyhe min su'in qalt imr'atu alazizi al'aana has:hasa alhaqu 'ana: rawdtuhu a'n nnafshi wa-'inahu la-mina as-sadiki:na] Yusuf 12:51 
He (the King) said to the women, 'What was the matter with you when you sought to seduce Joseph against his will?' They said, 'He kept away from sin for fear of Allah — we have known no evil against him.' The wife of the 'Aziz said, 'Now has the truth come to light. It was I who sought to seduce him against his will, and surely, he is the truthful.'

At the semantic level quote 2A uses seven predicates namely SAY, WHATS THE MATTER, SEDUCE, WHAT A SHAME., NOT KNOW, COME and BE TRUTHFULL. Predlicate one SAY argues to (him) referring to the king, it also argues to (they) referring to the women and to wife of Aziz. Predicate two WHAT THE MATTER does not refer to any argument. Predicate three SEDUCE argues to Joseph and it also argues to wife of Aziz. Predicate four WHAT A SHAME argues for two arguments: women and Joseph. Predicate five NOT KNOW argues for wife of Aziz. Predicate six COME argues for the truth. Predicate seven BE TRUTHFULL argues for Joseph.

At the schematic level quote $2 \mathrm{~A}$ sounds that the syntactic and the semantic features of quote $2 \mathrm{~A}$ explores some predicates and arguments of women language expressing accusation of harassment. This forces the women to hedge for their negative face, i.e. the public image that women do not want the others to surpass or go further. They also attempt to always tell the truth by quantification their speech.

By the same token quote 2B syntactically uses three language styles. Semantically it uses two predicates namely SAY and WHAT A SHMAE. Schematically quote 2B finally hedges for both keeping face and telling the truth. In Quote $2 \mathrm{~B}$, positive face is kept by the Arabic but sorcial exclamation term [hasha: le-Allah] roughly glossed as 'What a shame!' in modern times. The selection of certain words processes, such as negation marked by [ma:], demonstration carried out by [hatha:] meaning 'this' which is also used twice, the inclusive style processed by [illa] glossed roughly as 'but' and the endorsement done by [in] roughly glossed as 'actually' or 'certainly' in modern English, is intended to qualify the speech said by the Egyptian women regarding Prophet Joseph (see Quote 2B).

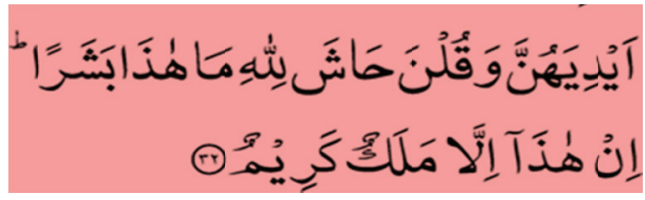

Quote 2B [qulnna hasha: li-Allahi ma: hatha: basharan in hatha: illa malakun kari:mun]Yusuf 12:31

And when they saw him they thought much of him and cut their hands, and said, 'Allah be glorified! This is not a human being; this is but a noble angel.'

\subsection{Telling the Truth}

To suffice, one language style is used in quote 3Aat syntactic level: the verbal. It is used twice to report what the queen said and to deliver a noble letter (see Quote 3A). It is important to note here that the quote uses the passive voice as the messenger is unknown. This selection of the voice suggests that the speaker is telling the truth and only the truth.

Quote 3A [qalat ya-ayyuha al-mala'u inni: ulqiya ilayya kita:bun kari:mun] An-Naml 27:29

The Queen said, "Ye chiefs, there has been delivered to me a noble letter.

At the semantic level, quote 3A uses two predicates namely SAY and DILEVER. Predicate one SAY argues for 'the queen' and 'the letter. Predicates two BE DILEVERED argues for both (me) referring to the 'Queen' and 'the letter'. Both the predicates and their arguments are very limited to Balqis, the Queen and the letter she received. This selection of the arguments and predicates suggests that the 'woman' is attempting to tell the truth regarding the issue she is discussing with her own people. The use of the predicate [ulqiya] roughly glossed as [be delivered] suggests that the letter was delivered via air as the Arabic, but passive voice word suggests that 'the letter was dropped from a high place'. The use of the term [kari:mun] roughly glossed as 'noble' in modern English implies that the content of the letter is 'welcoming'. And it is unlikely to be 'unwelcoming' or aggressive'. It is important to note here that the terms 'kari:mun] meaning 'kind' or 'generous' is used to describe both 'welcoming' people' and 'drinks' in the Semitic languages, such as Arabic and Hebrew. 


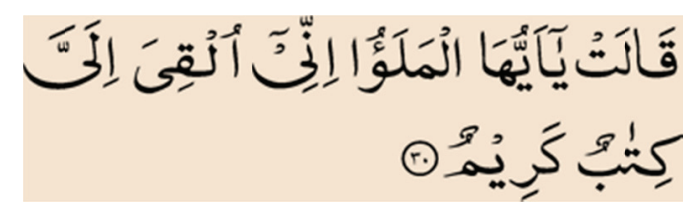

At the schematic level, quote $3 \mathrm{~A}$ sounds that the syntactic and the semantic features of quote $3 \mathrm{~A}$ explore some predicates and arguments of a woman's language who has received a letter from another king, i.e. Solomon who sent her a letter of surrender. The Queen reflects in front of her people on the letter. She uses some language that attempts to qualify the letter itself carefully, so she consults her own peoples to develop a proper reply to the sender. As there are readers and readers and listeners and listeners, it makes sense that the Queen attempts to qualify her speech by telling the truth of what she construed, i.e. realized in the letter.

By the same token, quote 3B syntactically uses two language styles. Semantically it uses five predicates namely AVERT, BEAR, SAY, BE UPON HER and SPEAK. Finally, schematically quote 3B hedges for telling only the truth (see Quote 3B).

In quote 3B, the Qur'anic discourse exemplifies for a potential but undesirable case in which the woman must give a witness on her own self. Therefore, it legislates for male couples who accuse their wives of adultery and who do not have witnesses except themselves. The QD mandates (to avoid punishment) a four-time witness be said that the husband is telling the truth. This vow is done by repeating "I swear by Allah that I'm telling the truth" four times. As those oaths are carried out on the positive part of the overlapping antonym, i.e. telling the truth, they sound insufficient or rather unreal on the logical level. Surprisingly, the holy Script of Islam accelerates another oath for the fifth time. This time the oath mandates the male husband say that 'Allah's curse be upon him if he be of the liars'. It is important to note here that the final oath is carried on the negative side of the antonym pair part of telling lies. This use suggests that the fifth time must look real on the logical level.

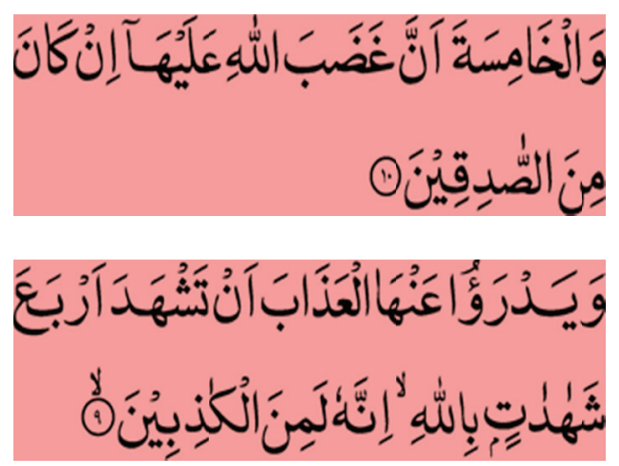

Quote 3B [wayadr'u a'anha: ala'thaba 'an tash-hada arbaa'a shahdatin bi-Allahi innahu laminna alkathibi:na ** wa-alkhamisatu 'an ghadaba Allai 'alayha: 'in ka:na mina assa:diqi:na ] An-Nur $24: 8$

But it shall avert the punishment from her if she bears witness four times in the name of Allah saying that he is of the liars. And her fifth oath shall be to say that the wrath of Allah be upon her if he speaks the truth

By checking the components of the fifth oath carried out by the accusing husband reveals two negative antonym pair parts, namely [la'nata] meaning (curse) and [ka:thibi:nal meaning (liars). However, drawing the "semantic values" for both suggests that the former is realized in -if not conditioned by, the latter (Hurford, pp. 187-197). In table 1, L1 as well as L4 look true. To confirm that someone is not cursed and not a liar is simply to agree that he is telling the truth (see Column 4 L4 in Table 1). To confirm that he is cursed and a lair is to agree that he is simply not telling the truth (see Column 4 L1 in Table 1). In natural language, people may express their feelings in response to a similar case by saying 'Damn, a liar!' The values in L2 and L3 are exclusively conditioned by one value (for these values, see Column 4 in Table 1). 
Table 1. The negative pair parts of the overlapping antonyms: cursed and liar

\begin{tabular}{lllcll}
\hline Preposition Ef consequence & $p$ & $q$ & $p \& 6$ & $p$ E $q$ fixes: \\
\hline L1: He is cursed, and he is a liar. & $\mathrm{T}$ & $\mathrm{T}$ & $\mathrm{T}$ & Being cursed and being a liar. \\
L2: He is cursed, but he is not a liar. & $\mathrm{T}$ & $\mathrm{F}$ & $\mathrm{F}$ & Only being cursed. \\
L3: He is not cursed, but he is a liar. & $\mathrm{F}$ & $\mathrm{T}$ & $\mathrm{F}$ & Only being a liar. \\
L4: He is not cursed, and he is not a liar. & $\mathrm{F}$ & $\mathrm{F}$ & $\mathrm{T}$ & Not being cursed and a liar. \\
\hline
\end{tabular}

Dissimilarly, quote 3B legislates for the female wife accused of adultery by her own husband to swear four times that he is a liar. As these oaths are carried on the negative part of the antonym, the values look real. As these vows can only maintain that her husband is not speaking the truth or rather a liar, they attempt to keep face. Another fifth oath is needed to reflect the truth of what she says. This time, the oath is carried out by 'Alla's wrath be upon her' if 'her husband speaks the truth'. In this final oath, only the negative part of wrath is used as a potential punishment for the wife. The other belongs to the husband himself. Responsibly and sensitively, this linguistic treatment attempts to diagnose as well as to fix a very fragile, familial rapport between a couple who is about to change their right of discourse. A right of discourse, such as birth, marriage, divorce and death, marks a certain circle of human life in which one moves from one circle to accommodate another.

In quote 5C, table 2 calculates the truth value for the extraordinary, fifth oath. This Qur'anic textual presentation maintains only truth value for the oath carried by the wife (see Column 4 L1). Overtly and directly, this meaning value explicates that the husband 'speaks the truth'. Covertly and indirectly, it also implicates that the wife is guilty of what is being accused of. In response to such a truth in real life, people usually tend to show anger as well as use some offensive words relate concubine. All the values in the other lines entail either a contradiction or nothing (see L2-L4 in Column 5). As implicated earlier, the Noble Quran discusses the traits associated with women's chastity and sexuality carefully and technically.

Table 2. The negative pair parts of the overlapping antonyms: Wrath and speak the truth

\begin{tabular}{|c|c|c|c|c|}
\hline Prepositions and consequences & $p$ & $q$ & $p \mathscr{E} q$ & $p \&$ q entails: \\
\hline $\begin{array}{l}\text { L1: He speaks the truth and wrath of Allah will } \\
\text { be upon her. }\end{array}$ & $\mathrm{T}$ & $\mathrm{T}$ & $\mathrm{T}$ & $\begin{array}{l}\text { He is not a liar; she is } \\
\text { guilty. }\end{array}$ \\
\hline $\begin{array}{l}\text { L2: He speaks the truth, but wrath of Allah won't } \\
\text { be upon her. }\end{array}$ & $\mathrm{T}$ & $\mathrm{F}$ & $\mathrm{F}$ & A contradiction. \\
\hline $\begin{array}{l}\text { L3: He doesn't speak the truth, but wrath of } \\
\text { Allah will be upon her. }\end{array}$ & $\mathrm{F}$ & $\mathrm{T}$ & $\mathrm{F}$ & A contradiction. \\
\hline $\begin{array}{l}\text { L4: He doesn't speak the truth and wrath of } \\
\text { Allah won't be upon her. }\end{array}$ & $\mathrm{F}$ & $\mathrm{F}$ & $\mathrm{F}$ & Nothing. \\
\hline
\end{tabular}

In both quotes, the QD surprisingly avoids any direct and explicit term that describes woman as a liar. In relevance, recent studies on "women language" have already revealed that women use language differently (Holmes, 2013, pp.258-283). Unlike men, women tend to use less directive terms, for instance. As they receive less directives, they incline to give directives. They also prefer to use words for an affective function, i.e. to socialize, rather than for a referential purpose, i.e. to inform. They also tend to avoid strong oaths; they prefer using empty words such as 'Gosh' and 'Heaven', for instance. One reason for doing so relates to the social role they play. At earlier stages, they are encouraged at home and later at school to play certain roles that fit them as daughters, sisters, wives and mothers later. Gradually, women tend to tailor their linguistic norms according to the social roles the society imposes on them.

\section{Conclusions and Implications}

\subsection{Introduction}

This section aims at concluding for the quotes discussed in the previous section. It also ends in some 
implication for pedagogy and research.

\subsection{Conclusions}

To conclude, the Qur'anic discourse (in the quotes referred to in this study) uses some language styles, processes, predicates and arguments that encourage women to keep face and to be polite. The context of the quotes referred to above is limited to certain contexts, such as giving birth at an old age and giving birth without marriage bond. As both quotes report what a woman should say in a context characterized either by hypersensitivity and abnormality, it is very probable that the Qur'anic discourse maintains both the public image as well as norms of polite speech for a Muslim woman.

Besides, the Qur'anic discourse referred to in this study include the selection as well use the use of some language, terms, styles, predicates and arguments that encourage women to keep face and tell the truth. The context of the quotes referred to above are limited to certain contexts including accusation of harassment and women crafty.

Finally, the Qur'anic discourse referred to in this study tends to select and used some language that encourages women to always tell the truth. The context of both quotes is limited to women's leadership and consultation and testimony in the case of accusation of adultery. In one example, the Qur'anic discourse goes further to quantify the speech of a wife accused by her own partner of bad deeds. In this case, the Qur'anic discourse acknowledges any potential wife (exceptionally, inclusively and stylistically) to quantify her testimony, i.e. speech, be relevant and be direct. Al-Heeh concludes (2018, pp.27-30) that the Qur'anic discourse under any circumstance does not allow for the woman and her counterpart the male, to describe herself or her, respectively as a liar (Al-Heeh, 2018).

\subsection{Implications for Pedagogy and Research}

To implicate for discourse analysts, it has been found in this study that the Qur'anic discourse maintains Grice's maxim of quality in women's language. Hence, the Qur'anic discourse highlights the importance of telling the truth. As the study is constrained by time factors and scope, the other maxims of collaborative speech namely quantity, style and manner are not covered in this study. Hereby, the researchers acknowledge that there is some evidence from the Quranic discourse the women's language is not only qualified but also quantified. The QD reports for a women leader who tends to not only to qualify her speech through consultation but to quantify her speech through providing them enough speech from a correspondence threatening her kingdom of conquer and war. Her language style sounds also direct and very relevant. Researchers whose main interest is discourse analysis can examine how women's language in the Qur'anic discourse is featured by brevity, relevance and straightforwardness.

Sociolinguists should also regard the main features of women's language. It has been argued in the first section of this study that the findings of some studies carried out on the main features of women's language mainly in the western modern cultures that women tend to use fuzzy or empty words. There is some evidence from the Qur'anic discourse that a woman or rather a Muslim female is encouraged highly to regard norms of face keeping, polite speech and truth telling. As many cultural norms in the Arabic speaking countries stem historically from the Noble Quran, it makes sense that the Arab, Muslim woman incline (probably subconsciously) to adapt or adjust her speech to these norms when speaking with others. The generalization of the findings of some universal studies on Muslim women is unlikely. Culture, i.e. a way of life, is a subject matter of privacy. Consequently, researchers whose main interest is gender and politeness should investigate the norms that govern women's talk in Arabic speaking countries.

Researchers whose main interests are stylistic pragmatics, translation and gender studies need to apply new approaches to the QD. For example, a critical discourse analysis (CDA) model can be used to interpret the deep thoughts, values, identities, roles and rights the QD gives about woman as human being. It also helps explain the proclivities and forces lving behind the selection and choice of the QD. It has been found in the study that the QD exemplifies for a woman who tends to do things right as well as the right things. In this sense, she behaves not only as a good manager but also as a great leader. The Qur'anic exemplification and manipulation mandate that the woman be a good leader at the nation level and a potential guardian at the family level. Besides roles, researchers should investigate the QD from a critical perspective to unearth the identity and its components the Noble Quran gives for the Muslim 
woman. Once it is approached from a stylistic and pragmatic view, the QD sounds very "responsive" and promising (Al-Heeh, 2017, p. 5).

Modern scholars of Islamic doctrine should regard more moderate outlooks to the QDs negotiating woman and familial guardianship and communal leadership. In one case, the QD tends on the syntactic level of the discourse to approve guardianship to male figures. Here, the QD exclusively sounds subiective. The semantic features of the words used regarding patriarch guardianship (also known as minor leadership) are illuminated only by 'social money' and physical capacity. Both sound relatively consistent with the nature of males as well as the Islamic, familial 'intimate economics' in which woman as wife is legally exempted from its burden. This fiscal and biological linkage looks very informative. On the deep level of meaning, the function of the predicate [qawwa:mu:nal meaning 'are too likely to be guardians' is, however, referential and evaluative. To be exclusively a directive one glossed as 「livaqu:mu:] meaning 'Be the only is unlikely. In respect, checking the "function of speech" is pivotal to reveal the real meanings the QD conveys and satisfies (Holmes, 2013, p. 258).

\section{References}

1. Al-Heeh, S. (2018). Embracing Woman Tenderly in the Noble Qur'anic Discourse under No Compulsion: An Attempt to Reconcile Modern Misanthropists and Traditional Misogynists. Forthcoming.

2. AL-Heeh, S. (2017). Affiliations of Place, Race, Face and Faith in the Opening of Al-Isra' Qur'anic

3. Al-Hidmi, S. and Abu-Ter, W (2017). An Investigation into the Phrases of Politeness Palestinian Ten-graders Exposed to When Learning English for Palestine (A graduation projected submitted to Department of English).

4. Argaman, S., Koppel, M., Pennebaker, J. W., \&Schler, J. (2007). Mining the blogosphere: Age, gender and the varieties of self-expression. First Monday, 12(9).

5. Broadridge, J., \& Learning, O. D. (2003). An investigation into differences between women's and men's speech. The University of Birmingham Centre for English Language Studies, 1-26.

6. English For Palestine (series). Ministry of education, Palestine.

7. Eliasoph, N. (1987). Politeness, power, and women's language: Rethinking study in language and gender. Berkeley Journal of Sociology, 32, 79-103.

8. Redstone, C.\& Cunningham, G. (2013), face2face ( $2^{\text {nd }}$ edition). Cambridge : CUP.

9. Fairclough, N. (2013). Critical discourse analysis: The critical study of language. Routledge.

10. Fairclough, N. (2010). Language and power. Pearson Education.

11. Gu, L. (2013, December). Language and Gender: Differences and Similarities. In 2013 International Conference on Advances in Social Science, Humanities, and Management (ASSHM-13). Atlantis Press.

12. Holmes, J. (2013). An introduction to sociolinguistics. Routledge.

13. Jinyu, D. O. N. G. (2014). Study on gender differences in language under the sociolinguistics. Canadian Social Science, 10(3), 92.

14. Kearns, K. (2000) Semantics. New York: St.

15. Lakoff, R. (1973). Language and woman's place. Language in society, 2(1), 45-79.

16. Mirzaei, A., \&Eslami, Z. R. (2013). Exploring the variability dynamics of wedding invitation discourse in Iran. Journal of Pragmatics, 55, 103-118.

17. Norbert Schmitt (editor: 2002) An Introduction to Applied Linguistics. London: Hodder Education.

18. The Quranic Discourse: Available at: www.alislam.org (Accessed on March 3, 2018).

19. Shepherd, L. J. (2010). Women, armed conflict and language-Gender, violence and discourse. International Review of the Red Cross, 92(877), 143-159.

20. Van Dijk, T. A. (1998). Ideology: A multidisciplinary approach. Sage. Denzin, N. K., \& Lincoln, Y. S. (2011). The SAGE handbook of qualitative research. Sage

21. Xia, X. (2013). Gender differences in using language. Theory and Practice in Language Studies, 3(8), 1485. 


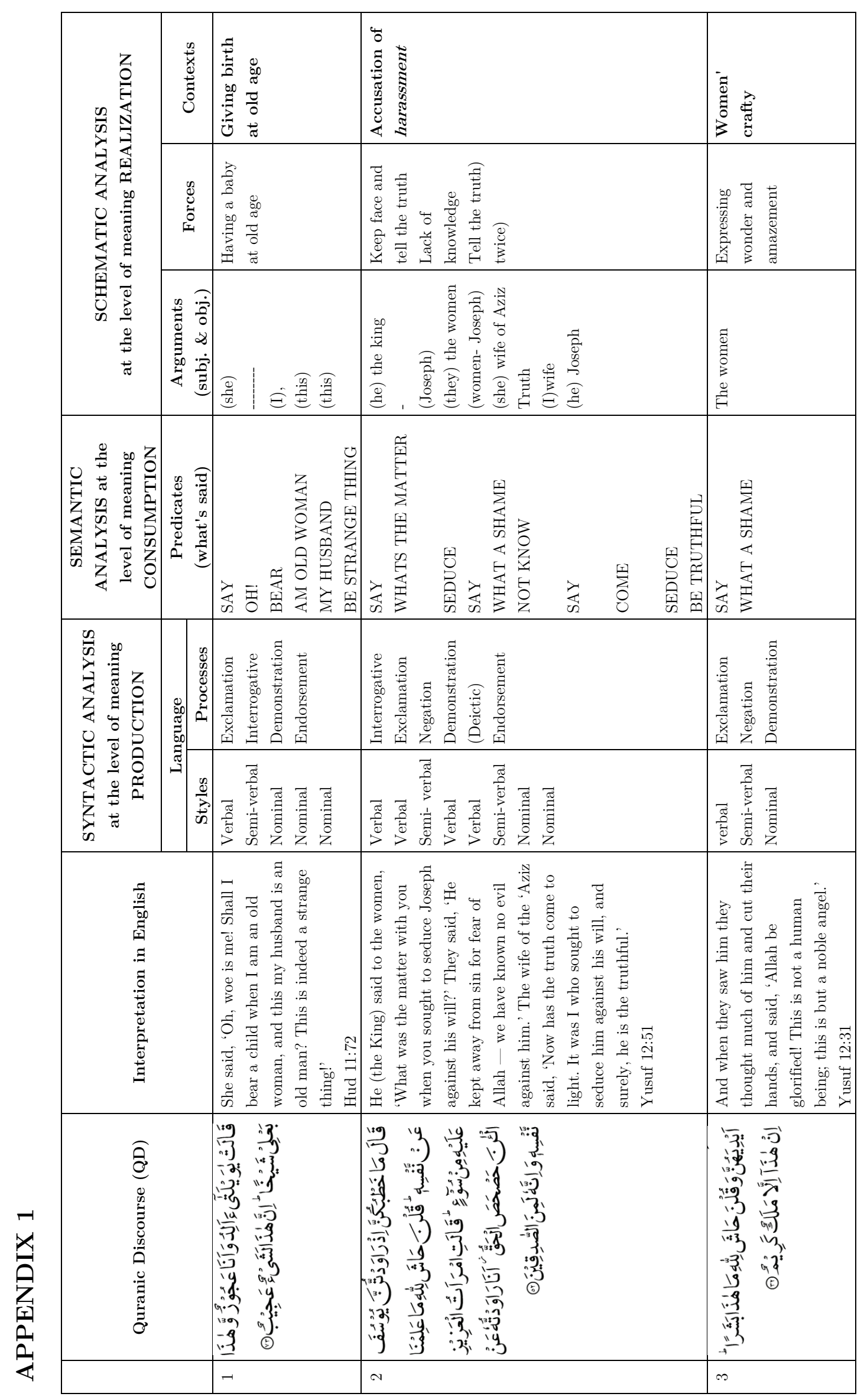




\begin{tabular}{|c|c|c|c|c|c|c|}
\hline 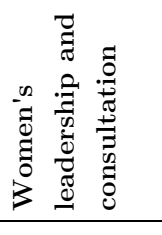 & 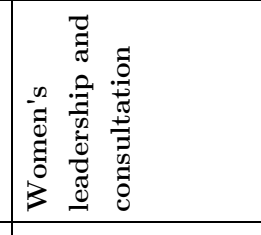 & 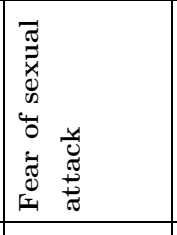 & 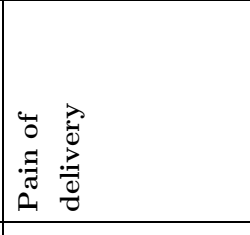 & 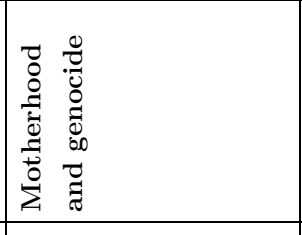 & 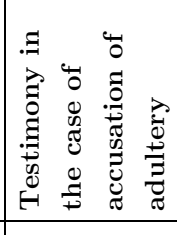 & \\
\hline 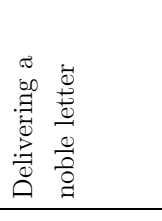 & 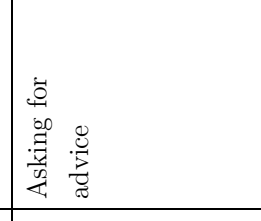 & 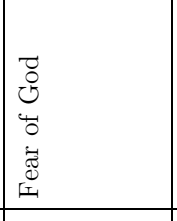 & 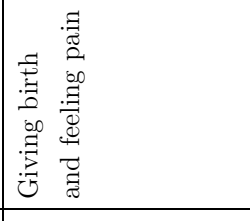 & 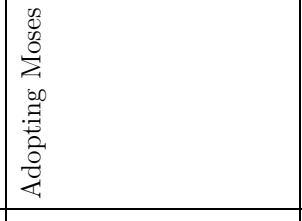 & 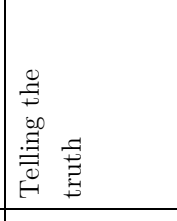 & \\
\hline 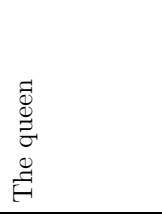 & 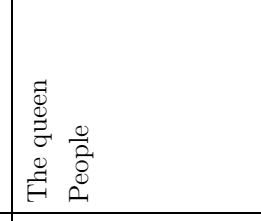 & 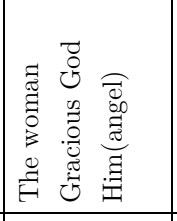 & 苞 & 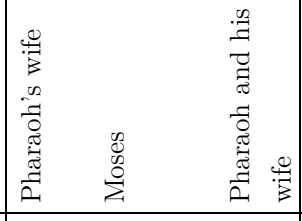 & 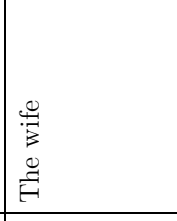 & \\
\hline 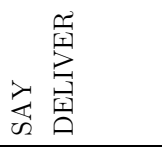 & 窟 & 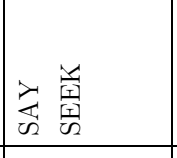 & 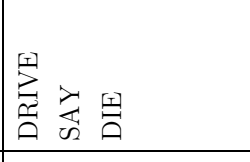 & 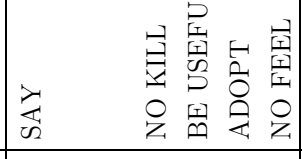 & 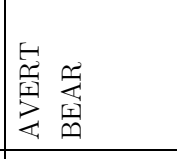 & \\
\hline 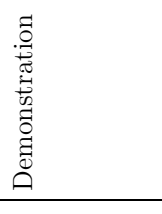 & 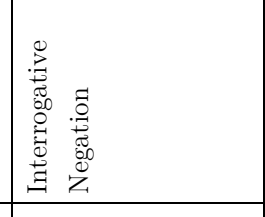 & 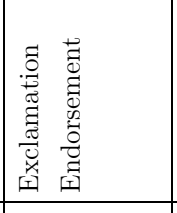 & 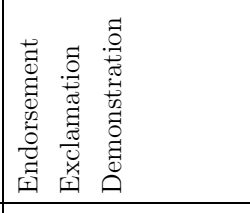 & 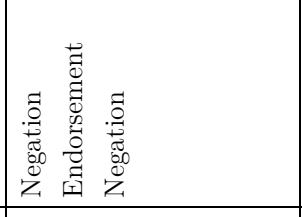 & 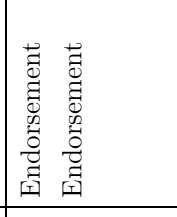 & 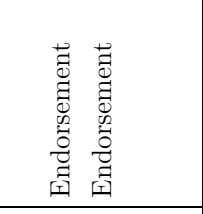 \\
\hline 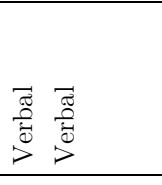 & 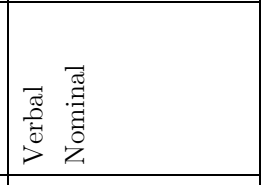 & 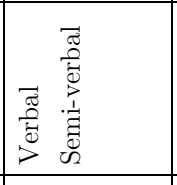 & 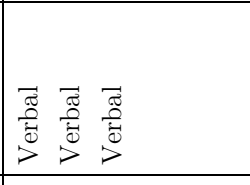 & 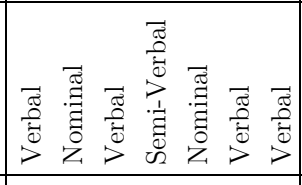 & 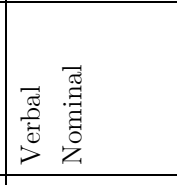 & 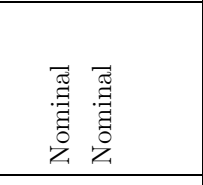 \\
\hline 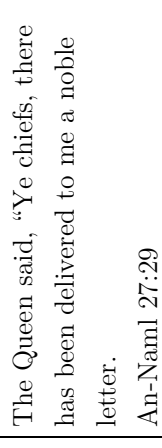 & 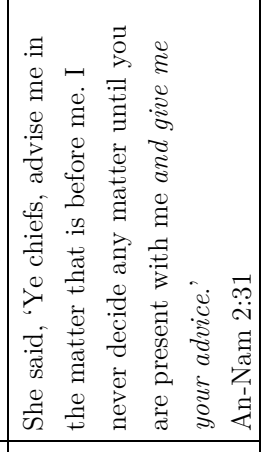 & 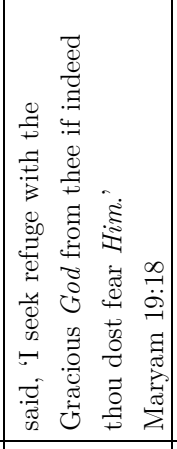 & 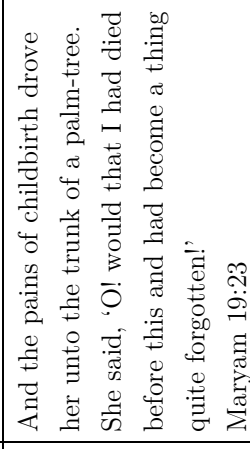 & 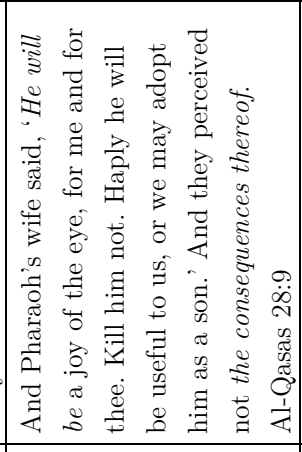 & 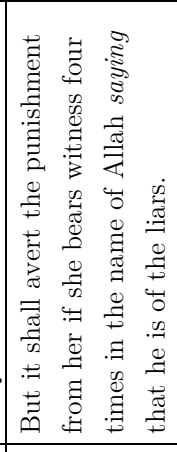 & 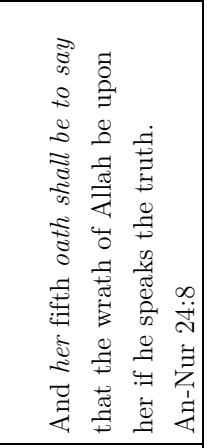 \\
\hline 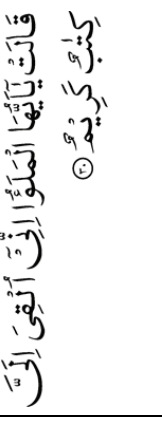 & 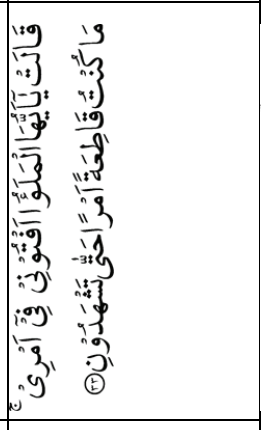 & 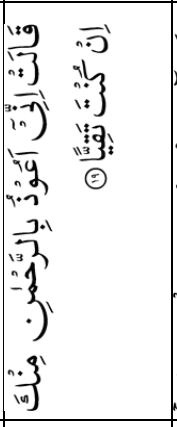 & 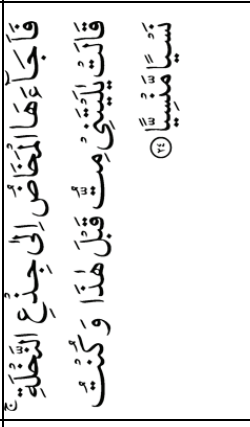 & 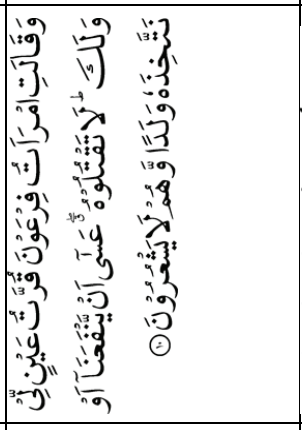 & 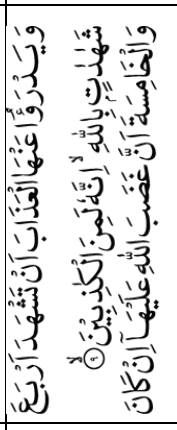 & 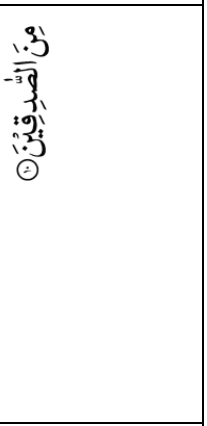 \\
\hline$r$ & 10 & 0 & $r$ & $\infty$ & $\infty$ & \\
\hline
\end{tabular}




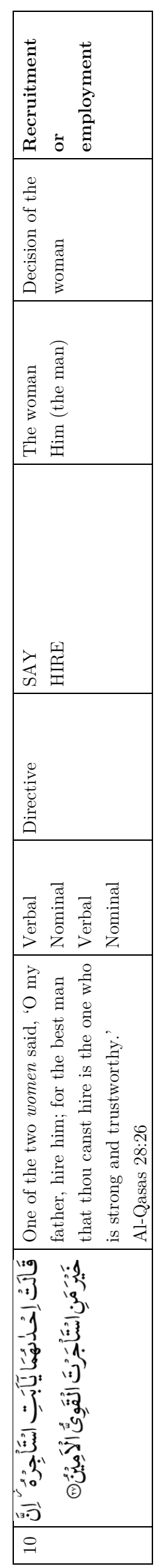

